www.jmscr.igmpublication.org

Impact Factor (SJIF): 6.379

Index Copernicus Value: 79.54

ISSN (e)-2347-176x ISSN (p) 2455-0450

crossrefDOI: https://dx.doi.org/10.18535/jmscr/v6i8.167

Journal Of Medical Science And Clinical Research

\title{
Clinical and Demographic Profile of Acute Organophosphate Poisoning at a Tertiary Care Hospital in Coastal Karnataka
}

\author{
Authors \\ Dr Akshatha Rao Aroor ${ }^{*}$, Dr K Sundara Bhat ${ }^{2}$ \\ ${ }^{1}$ Associate Professor, Department of General Medicine, Father Muller Medical College, Kankanady, \\ Mangalore, Karnataka, India \\ ${ }^{2}$ Professor, Department of General Medicine, Father Muller Medical College, Kankanady, Mangalore, \\ Karnataka, India \\ *Corresponding Author \\ Dr Akshatha Rao Aroor \\ Email: akshatharao0502@gmail.com
}

\begin{abstract}
Background: Acute pesticide poisoning has become a major public health problem world-wide, especially in developing countries like India. Organophosphate poisonings accounts for most of the self-poisoning deaths in southern and central India.

Aim: To study the clinical and demographic profile, risk factors, clinical features, complications and factors modifying the outcome in acute organophosphate poisoning.

Methods: This study was carried out at a tertiary care hospital in coastal Karnataka. The study included all cases of acute organophosphate poisoning who were more than 18 years of age admitted in intensive care unit during the study period from January 2013 to December 2017.

Results: A total of 120 cases of acute OP poisoning were included. The mean age was $39.1 \pm 15.2$ years with a M:F ratio of 2.5:1. All cases were suicidal and ingestion was the route of poisoning in all the cases. Poisoning was more common among married population (74.2\%), illiterates (58.3\%) and farmers (32.5\%). History of marital conflict (25\%), financial problems (24.2\%) and alcohol abuse (29.2\%) were common risk factors. Nausea and vomiting (76.7\%) was the commonest symptom and bradycardia (29.2\%) was the most common physical finding. Acute respiratory distress syndrome (ARDS) was significantly associated with mortality $(28.6 \%)$.

Conclusions: $O P$ poisoning is a major health problem in the young population especially in developing countries like India. Prompt, early management may help in reducing the complications and improve the outcome in these patients.
\end{abstract}

Keywords: Acute respiratory distress syndrome, Clinical profile, Organophosphate, Outcome.

\section{Introduction}

Poisoning is a global health issue occurring all over the world involving people of all age groups, both sex, from all economic and ethnic groups. According to the WHO, approximately 2,00,000 deaths occur due to OP poisoning. ${ }^{[1]}$ Majority of the suicidal cases occur due to pesticide poisoning. As per the WHO estimates, more than $90 \%$ of fatal poisoning cases are seen in middle and low income countries i.e. the developing 
countries in general and agricultural countries in particular. ${ }^{[2]}$ Acute pesticide poisoning (APP) account for significant morbidity and mortality worldwide, more so in developing countries. ${ }^{[3], \text { [4] }}$ Organophosphate (OP) compounds were first developed by Schrader before and during the Second World War. OP compounds have become one of the most commonly used insecticides for the past four decades. ${ }^{[5]}$ In India, due to low cost and easy accessibility of the compound, it is the most common mode of poisoning fatalities as a source of both intentional and unintentional poisoning. ${ }^{[6]}$ According to various studies, OP compound is the commonest poisoning substance in India. ${ }^{[7], ~}{ }^{[8]}$ The estimated mortality rate with organophosphate poisoning in our country is around $7-12 \%$. $^{[9]}$

OP compounds are highly toxic substances, which result in high mortality rate. They act by inhibiting the enzyme acetylcholinesterase leading to various muscarinic and nicotinic manifestations. These include bradycardia, hypotension (muscarinic), tachycardia (nicotinic), increased salivation/ lacrimation, miosis, excessive sweating, nausea, vomiting, diarrhea, pain abdomen, fecal and urinary incontinence. ${ }^{[10]}$ CNS manifestations include anxiety, restlessness, convulsion, coma, chyne-stokes breathing, respiratory and cardiovascular failure. ${ }^{[11]}$

Intermediate syndrome or type II paralysis can occur after 24-96 hours after acute cholinergic crisis. Incidence of intermediate syndrome is variable ranging from $8-50 \%$. ${ }^{[12]}$ Chronic OP poisoning can cause organophosphate-induced delayed neuropathy, mostly seen in agricultural workers. ${ }^{[13]}$ Delay in the diagnosis and treatment can lead to worse outcome. Hence the knowledge of the pattern of poisoning would help us in early diagnosis and management of poisoning, which in turn should result in a reduction of morbidity and mortality.

\section{Materials and Methods}

This is a retrospective, record based study conducted at a tertiary care hospital in coastal
Karnataka. The institutional ethical clearance was obtained prior to the study. The clinical and demographic data were recorded in a predesigned proforma. The study included all cases of OP poisoning in adults $>18$ years admitted during the period of January 2013 to December 2017. The diagnosis of OP compound was based on definite history of OP consumption, presentation of the container from which the poison had been consumed, typical clinical features, clinical examination findings and atropine tolerance. Patients with history of exposure to a mixture of organophosphorus and other poison were excluded from the study. Complete medical record of all such cases which included demographic data, mode and route of poisoning, cause of poisoning, symptoms and signs, complications, management, duration of hospitalization and clinical outcome were retrieved from the patient's information reports. Patients were treated according to the standard protocol of OP poisoning with atropine, pralidoxime and supportive care including mechanical ventilation, as required and dealt upto recovery or death from poisoning.

\section{Statistical analysis}

The data collected were documented using Statistical Package for the Social Sciences (SPSS) version 23. Statistical analysis was done using descriptive statistics such as mean, frequency, standard deviation and percentages. The association of clinical parameters with outcome was analysed using Chi-square test and Fischer's exact test for categorical data.

\section{Results}

A total of 120 cases of confirmed OP poisoning cases $>18$ years of age were admitted during the study period. There was a wide variation in age ranging from 19-84 years with a mean age of 39.1 \pm 15.2 years (mean $\pm \mathrm{SD}$ ). Majority of the patients were in the age group of 21-30 years (27.5\%). [Table 1] Males were more commonly affected with a M: F ratio of 2.5:1. [Figure 1] Maximum numbers of cases were recorded in the year 2015 
and 2017 (24.2\% each). Clustering of cases was found during the months of March to June.

Poisoning was found to be more common among married population $(74.2 \%)$ and illiterates $(58.3 \%)$. Majority of the patients hailed from rural area (79.2\%). Most of the patients belonged to the Hindu community (78.3\%). Among the cases, 39 were farmers $(32.5 \%)$. The mode of poisoning was suicidal in all the cases. Ingestion was the route of exposure in all the patients. As evident from the table, most common risk factor for suicidal consumption of poison was marital conflict $(25 \%)$ followed by financial stress $(24.2 \%)$. [Table 2] Patient suffering from psychiatric illness were at high risk for suicidal consumption of pesticide poison $(20.8 \%)$. In our study, 35 patients $(29.2 \%)$ had chronic history of alcohol intake.

Muscarinic symptoms were found to be more common than nicotinic in these patients. The commonest symptom was nausea and vomiting (76.7\%) followed by abdominal pain (35.8\%), excessive perspiration (28.3\%) and excessive salivation $(24.2 \%)$. The commonest finding was bradycardia (29.2\%) followed by altered sensorium (27.5\%) and lung crepitations (24.2\%). [Table 3]

In our study, we found various complications such as ARDS in 7 patients (5.8\%), aspiration pneumonia in 6 patients $(5 \%)$, sudden cardiac arrest in 5 patients $(4.1 \%)$, acute respiratory failure in 7 patients (5.8\%), type 1 paralysis in 6 patients $(5 \%)$, intermediate syndrome in 3 patients $(2.5 \%)$ and sepsis with multi-organ dysfunction in 1 patient $(0.8 \%)$. We found that mortality was higher in patients who presented with dyspnea (50\%), lung crepitations (64.3\%) and ARDS $(28.6 \%)$ which was statistically significant (p value $=0.000$ ). Also, all the patients who expired needed mechanical ventilation and the association was statistically significant $(\mathrm{p}$ value $=0.000$ ).

We found that 95 patients $(79.2 \%)$ improved, 14 patients $(11.7 \%)$ expired and 11 patients $(9.2 \%)$ were discharged against medical advice. The duration of hospital stay is depicted in Table 4.
Mortality was found to be maximum in patients (71.4\%) within 4 days of hospital admission and was statistically significant $(\mathrm{p}$ value $=0.000$ )

Table 1: Age-wise distribution of cases

\begin{tabular}{|l|c|c|}
\hline Age & No of cases & Percentage \\
\hline 20 and below & 13 & $10.8 \%$ \\
\hline $21-30$ & 33 & $27.5 \%$ \\
\hline $31-40$ & 25 & $20.8 \%$ \\
\hline $41-50$ & 22 & $18.3 \%$ \\
\hline $51-60$ & 16 & $13.3 \%$ \\
\hline Above 60 & 11 & $9.2 \%$ \\
\hline Total & 120 & $100.0 \%$ \\
\hline
\end{tabular}

Table 2: Risk factors contributing to poisoning

\begin{tabular}{|l|c|c|}
\hline Causes & Number of cases & Percentage \\
\hline Marital conflict & 30 & $25 \%$ \\
\hline Financial stress & 29 & $24.2 \%$ \\
\hline Failure in examinations & 9 & $7.5 \%$ \\
\hline Psychiatric disorder with & 25 & $20.8 \%$ \\
\hline $\begin{array}{l}\text { Discordance } \\
\text { parents }\end{array}$ & 7 & $5.8 \%$ \\
\hline Love affairs and domestic & 7 & $5.8 \%$ \\
\hline $\begin{array}{l}\text { Social and } \\
\text { problems }\end{array}$ & 7 & $5.8 \%$ \\
\hline Chronic illness & 35 & $5.8 \%$ \\
\hline Alcohol abuse & 8 & $29.2 \%$ \\
\hline Unknown reason & & $6.7 \%$ \\
\hline
\end{tabular}

Table 3: Symptoms and signs in OP poisoning

\begin{tabular}{|l|c|}
\hline \multicolumn{1}{|c|}{ Symptom } & Number of cases (\%) \\
\hline Nausea/vomiting & $92(76.7 \%)$ \\
\hline Excessive salivation & $29(24.2 \%)$ \\
\hline Excessive lacrimation & $21(17.5 \%)$ \\
\hline Perspiration & $34(28.3 \%)$ \\
\hline Abdominal pain & $43(35.8 \%)$ \\
\hline Bronchorrhoea & $8(6.7 \%)$ \\
\hline Diarrhoea & $9(7.5 \%)$ \\
\hline Stool/urine incontinence & $4(3.3 \%)$ \\
\hline Dyspnoea & $15(12.5 \%)$ \\
\hline Agitation & $10(8.3 \%)$ \\
\hline Muscle twitching & $7(5.8 \%)$ \\
\hline Signs & $18(15 \%)$ \\
\hline Oro-nasal frothing & $29(24.2 \%)$ \\
\hline Crepitations & $35(29.2 \%)$ \\
\hline Bradycardia & $7(5.8 \%)$ \\
\hline Tachycardia & $18(15 \%)$ \\
\hline Miosis & $33(27.5 \%)$ \\
\hline Altered sensorium & $7(5.8 \%)$ \\
\hline Fasciculations & $4(3.3 \%)$ \\
\hline Seizure & \\
\hline
\end{tabular}


Table 4: Correlation of outcome with the hospital stay

\begin{tabular}{|l|c|c|c|}
\hline Duration & Survived (\%) & Expired (\%) & Total \\
\hline More than 7 days & $46(43.4 \%)$ & $1(7.1 \%)$ & 47 \\
\hline 1-4 days & $16(15.1 \%)$ & $10(71.4 \%)$ & 26 \\
\hline 4-7 days & $44(41.5 \%)$ & $3(21.4 \%)$ & 47 \\
\hline
\end{tabular}

Figure 1: Sex distribution of cases

Figure 1:Sex distribution of cases

\section{Discussion}

The highest incidence of OP poisoning is seen in India. ${ }^{[14]}$ Suicidal and non-suicidal OP poisoning is a major health problem in rural parts of India, with rapidly increasing incidence rate. ${ }^{[15]}$

Majority of the patients were in the age group of 21-30 yrs $(27.5 \%)$ This is in comparison to a study done by Tanveer et $\mathrm{al}^{[16]}$ where the mean age was 31.5 years and Chintale $\mathrm{KN}$ et al. ${ }^{[17]}$ The people in young age group are described to be the most ambitious and more vulnerable to various emotional conflicts that may occur during this phase of life which may predispose them to poisoning.

In our study, male to female ratio was 2.5:1. In the present study, incidence of poisoning was higher in males $(71.7 \%)$ than in females $(28.3 \%)$. Similar trend was observed in study done by Tanveer et al ${ }^{[16]}$ and Shah NM. ${ }^{[18]}$ This may be because males are the main working group in outdoor field, i.e. they are more involved in spraying crops in the farms. In contrast, a study done by Banerjee et $\mathrm{al}^{[19]}$ found females to be more commonly affected. In our study, higher incidence of poisoning was seen in illiterates $(58.3 \%)$ than literates $(41.7 \%)$. This is similar to study done by
Chintale et al ${ }^{[17]}$ and Gupta $\mathrm{BD}^{[20]}$ which suggests that illiteracy may be contributing to poisoning. Poisoning was found to be commoner in married population, a finding similar to a study done by Chintale et al ${ }^{[17]}$ and Kora et al. ${ }^{[21]}$

The intention of poisoning was suicidal in all the cases, which is in comparison with other studies. ${ }^{[16], ~[17] ~}$ This could be because it is cheap, easily available and used as a major pesticide in agriculture throughout India. Ingestion was the route of poisoning in all the cases which is in par with other studies. ${ }^{[17]}$ Farming was the most common occupation in patients which is a contributing factor for poisoning in these patients.

Highest incidence of poisoning was noted in the months of March to June. This is partially comparable to the study done by Kar et al [22] where the incidence of poisoning was highest during the month of May to August. In contrast, study done by Chintale et al ${ }^{[17]}$ had maximum cases from August to December and Muhammed IS et $\mathrm{al}^{[23]}$ where clustering was found from July to September. In our study, there were no cases of accidental poisoning whereas in the above mentioned studies, accidental exposure was seen in $14-22 \%$ of cases. Thus the seasonal variation in our study as compared to other studies could be explained by the fact that August to December are the usual months of spraying crops and there are more chances of accidental exposure to the compound during this period in other studies.

The factors contributing to poisoning were marital conflict followed by financial problems, social and domestic problems. This is partially comparable to the study done by Chintale et al ${ }^{[17]}$ where social and domestic problems (50.80\%), marital friction (11.60\%) and alcohol abuse $(9.82 \%)$ were important risk factors.

The commonest symptom was nausea and vomiting followed by abdominal pain, excessive perspiration and salivation. This is in comparison to a study done by Shah et $\mathrm{al}^{[18]}$ and contrast to the study done by Chintale et $\mathrm{al}^{[17]}$ and Khan FY et al ${ }^{[24]}$ where excessive salivation was the commonest symptom. The commonest finding was 
bradycardia in $29.2 \%$ patients which is comparable with studies by Shah et al. ${ }^{[18]}$ However, miosis was found in fewer patients in our study as compared to other studies. ${ }^{[17], ~[23]}$ The clinical manifestations could vary depending on the amount of poison consumed, delay in the arrival to the hospital and delay in the treatment.

The commonest complication noted in study was ARDS (5.8\%) and acute respiratory failure (5.8\%) followed by aspiration pneumonia and type 1 paralysis (5\% each). This is partially comparable to a study done by Edwin George et al ${ }^{[25]}$ where acute respiratory failure and pneumonia was found in $14 \%$ and $15 \%$ patients respectively. A study by Shah et $\mathrm{al}^{[18]}$ found ARDS in $12 \%$ patients which are partially comparable with our study.

In our study, mortality was observed in $11.7 \%$ of patients. This is comparable to study done by Chintale et al. ${ }^{[17]}$ However, study done by Shah et al ${ }^{[18]}$ and Tanveer et al ${ }^{[16]}$ had higher mortality $(33 \%)$ as compared to our study. This could be because of higher rate of complications observed in their study. Mortality was found to be significantly higher in patients with ARDS which correlates with a study by Shah et al. ${ }^{[18]}$ hours of admission.

The limitations of the study include retrospective nature of the study design. Also, serum cholinesterase levels could not be done as this is a retrospective study and due to non-availability of the test kit in our hospital.

\section{Conclusions}

ARDS was significantly associated with mortality in acute organophosphate poisoning. OP poisoning is a major health problem in the young population especially in developing countries like India. Prompt, early management may help in reducing the complications and improve the outcome in these patients.

\section{References}

1. Clinical management of acute pesticide intoxication: Prevention of suicidal behaviours: WHO;2008

2. Batra AK, Koeliya AN, Jadhan GU. Poisoning: an unnatural cause of morbidity and mortality in rural India. $\mathbf{J}$ Assoc Physicians India 2003;51:955-59.

3. Kishi M, Ladou J. International pesticide use. Int J Occup Environ Health 2001;7: 259-65.

4. Jeyaratnam J. Acute pesticide poisoning: a major global health problem. World Health Stat Q $1990 ; 43: 139-44$.

5. Fukuto TR. Mechanism of action of organophosphorus and carbamate insecticides. Environ Health Perspect 1990;87:245-54.

6. Corriols M, Marin J, Berroteran J, Lozano LM, Lundberg I, Thorn A. The Nicaraguan Pesticide Poisoning Register: constant underreporting. Int $J$ Health Serv 2008;3:773-87.

7. B. Maharani and N. Vijayakumari., Profile of poisoning cases in a Tertiary care Hospital, Tamil Nadu, India. J App Pharm Sci 2013;3:091-4.

8. Kumar SV, Venkateswarlu B, Sasikala M, Kumar G V. A study on poisoning cases in a tertiary care hospital. J Nat Sc Biol Med 2010;1:35-9.

9. Bawaskar HS, Joshi SR. Organophosphorus Poisoning in Agricultural India Status in 2005. J Assoc Physicians India 2005;53:422-4.

10. Lotti M, Moretto A. Cholinergic symptoms and Gulf War syndrome. Nat Med. 1995;1:1225-6.

11. Singh G, Khurana D. Neurology of acute organophosphate poisoning. Neurol India. 2009;57:119-25.

12. Yang CC, Deng JF. Intermediate syndrome following organophosphate insecticide poisoning. J Chin Med Assoc 2007;70:467-72. 
13. Emerick GL, Peccinini RG, de Oliveira GH. Organphosphorus-induced delayed neuropathy: A simple and efficient therapeutic strategy. Toxicol Lett 2010;192:238-44.

14. Rodgers ML. OP poisoning. Am J Emerg Med 2006;22:335-44.

15. Gupta SK, Peshin SS, Srivastava A, Kaleekal T, Pandian TV. An epidemiological pattern of poisoning in India. Pharmacoepidemiol Drug Saf 2002; 11:73-4.

16. Banday TH, Tathineni B, Desai MS, Naik V. Predictors of morbidity and mortality in organophosphorus poisoning: a case study in rural hospital in Karnataka, India. N Am J Med Sc 2015;7:259-65.

17. Chintale KN, Patne SV, Chavan SS. Clinical profile of organophosphorus poisoning patients at rural tertiary health care centre. International Journal of Advances in Medicine 2017;3:268-74.

18. Shah NM, Mundhra SH. Clinical profile of organophosphate poisoning at a tertiarycare center. International Journal of Medical Science and Public Health 2016;5:1621-5.

19. Banerjee I, Tripathi S, Roy AS. Clinicoepidemiological characteristics of patients presenting with organophosphorus poisoning. N Am J Med Sci 2012;4:14750.

20. Gupta BD, Vaghela PC. Profile of Fatal Poisoning in and around Jamnagar. Journal of Indian Academy of Forensic Medicine 2005;27:145-8.

21. Kora SA, Doddamani GB, Halagali GR, Vijayamahantesh SN, Boke Umakanth. Socio-demographic Profile of the Organoposphorus Poisoning Cases. J Clin Diagn Res 2011;5:953-6.
22. Kar SM, Timsinha S, Agrawal P. An Epidemiological study of Organophosphorus Poisoning at Manipal Teaching Hospital, Pokhara, Nepal. Journal of Indian Academy of Forensic Medicine 2010;32:108-9.

23. Muhammad IS, Rushd J, Rai M. The analysis of organophosphates poisoning cases treated at Bahawal Victoria Hospital, Bahawalpur in 2000-2003. Pak J Med Sci 2006;22:244-9.

24. Khan FY, Kamha AM, Ibrahim AS, D'souza A. One year study of patients with acute organophosphate insecticide poisoning admitted to the intensive care unit of Hamad General Hospital, Doha, State of Qatar. Journal of Emergency Medicine Trauma and Acute Care 2006;6:16-20.

25. Edwin J George, Jayaraj K, John J Manjaly, Raghunath M .Clinical profile and outcome of organophosphate poisoning cases in a tertiary care hospital in central Kerala. International Journal of Recent Trends in Science and Technology 2015;14:338-43. 